\title{
Maternal and Perinatal outcomes of oligohydramnios in a tertiary care hospital in Salem, Tamil Nadu, India
}

\author{
Jeyamani B. ${ }^{1}$, Anurekha J. P. ${ }^{1}$, Arun Daniel J. ${ }^{2 *}$
}

\begin{abstract}
${ }^{1}$ Department of Obstetrics and Gynecology, Government Mohan Kumaramangalam Medical College and Hospital, Salem, Tamil Nadu, India

${ }^{2}$ Department of Community Medicine, Aarupadai Veedu Medical College and Hospital, A unit of Vinayaka Mission University, Salem, Tamil Nadu, India
\end{abstract}

Received: 21 February 2019

Accepted: 01 April 2019

\section{*Correspondence:}

Dr. Arun Daniel J.,

E-mail: drdanfi@yahoo.co.in

Copyright: (c) the author(s), publisher and licensee Medip Academy. This is an open-access article distributed under the terms of the Creative Commons Attribution Non-Commercial License, which permits unrestricted non-commercial use, distribution, and reproduction in any medium, provided the original work is properly cited.

\section{ABSTRACT}

Background: Oligohydramnios is the term coined for a condition where the amount of liquor amnii is less than 200 $\mathrm{ml}$ at term. Using an ultrasonogram, oligohydramnios can be deliberated when the vertical pocket of liquor is less than $2 \mathrm{~cm}$ or when amniotic fluid index (AFI) is less than $5 \mathrm{~cm}$. Oligohydramnios is reported to occur in 1 to $5 \%$ of total pregnancies. It has been associated with adverse maternal and foetal outcomes.

Methods: This hospital-based follow-up study was conducted among 540 pregnant women at 37 weeks attending to the Department of Obstetrics and Gynaecology for a period of 1 year from January to December 2018. All included pregnant women were subjected to routine ultrasound examination and assessment of amniotic fluid volume using Amniotic fluid index.

Results: The incidence of oligohydramnios was $17.04 \%(n=92)$ among the included women and $62 \%(n=57)$ among them were primigravida. Among those women diagnosed with Oligohydramnios, the caesarean section rate was $56.5 \%(n=52)$, the common indications for LSCS being fetal distress $44.2 \%(n=23)$ and IUGR $34.6 \%(n=18)$. The oligohydramnios pregnancies had more associated post-dated deliveries $(28.3 \%)$, pregnancy induced hypertension $(10.9 \%)$ and gestational diabetes $(8.7 \%)$. It was also associated with higher incidence of low birth weight $(27.2 \%)$, NICU admissions (32.6\%), congenital anomalies (3.3\%) and fetal deaths (5.4\%).

Conclusions: The study showed that an amniotic fluid index of less than 5 at term was associated with adverse maternal and perinatal pregnancy outcomes emphasizing the importance of amniotic fluid volume surveillance during the antenatal period.

Keywords: Amniotic fluid index, Maternal and perinatal outcomes, Oligohydramnios

\section{INTRODUCTION}

Amniotic fluid is a clear to mild yellowish, faintly alkaline, thin fluid with low specific gravity, which covers the fetus inside the amniotic sac during pregnancy. ${ }^{1}$ The volume of amniotic fluid varies with the gestational age measuring about $50 \mathrm{ml}$ at 12 weeks, 400 $\mathrm{ml}$ at 20 weeks and 1 litre at 36-38 weeks. The volume of amniotic fluid diminishes thereafter till at term it measures about 600-800 ml. ${ }^{2}$ Amniotic fluid helps in maintaining a well hydrated scaffold for free movement and growth of the fetus during the ante-natal period and providing protection from umbilical cord compression during labour. ${ }^{1}$ Oligohydramnios is the term coined for a condition where the amount of liquor amnii is less than $200 \mathrm{ml}$ at term. Using an ultrasonogram, oligohydramnios can be deliberated when the vertical pocket of liquor is less than $2 \mathrm{~cm}$ or when amniotic fluid 
index (AFI) is less than $5 \mathrm{~cm}$. Oligohydramnios is reported to occur in 1 to $5 \%$ of total pregnancies. ${ }^{3}$ This condition can pose serious threats on the maternal and fetal dimensions of pregnancy. The common maternal complications include prolonged labor; mal-presentation and fetal complications include abortion, cord compression, deformity due to intra-amniotic adhesions, pulmonary hypoplasia, potter's syndrome, club foot and hand and hip dislocation. ${ }^{4}$ The present research has been done with an objective to evaluate the maternal and perinatal outcome associated with oligohydramnios in a tertiary care hospital of Salem, Tamil Nadu, India.

\section{METHODS}

This hospital-based follow-up study was conducted among 540 pregnant women attending to the Department of Obstetrics and Gynaecology for a period of 1 year from January to December 2018. Initially an approval from the Institution Ethics Committee was obtained for conduct of the study. Women attending the Obstetrics outpatient department or the labour room at or after 37 weeks of gestation with singleton pregnancy, intact membranes, known and documented LMP in those with regular cycles or by ultrasonogram at the first trimester, without known uterine anomalies and having AFI measurement within 3 days of delivery included in this study. Women with congenital malformation, previous caesarean section, medical disorder like cardiac disease, intrauterine death of the foetus, multiple pregnancy, premature rupture of membranes and post-dated pregnancy were excluded from this study.

The pregnant women included in the study were interviewed using a semi-structured questionnaire and socio-demographic data, relevant clinical history and examination findings were recorded. The participants were then subjected to routine ultrasound examination and assessment of amniotic fluid volume using Amniotic fluid index (AFI).

\section{Amniotic fluid index technique}

The participant was informed regarding the procedure and consent was obtained. Then she was asked to lie down in supine position and a curvilinear transducer was used to examine the uterus sonographically. The maternal abdomen was divided into virtual quadrants taking the umbilicus, symphysis pubis and the fundus as the reference points. The largest vertical pocket in each quadrant is measured sonographically and the sum of the four measurements $(\mathrm{cm})$ was computed as the AFI.

Oligohydramnios was defined when the maximum vertical pocket of liquor was less than $2 \mathrm{~cm}$ or when amniotic fluid index (AFI) was less than $5 \mathrm{~cm}$. AFI 5-8 $\mathrm{cm}$ as borderline oligohydramnios and AFI $8-18 \mathrm{~cm}$ as normal amniotic fluid index.

\section{Statistical analysis}

Data entry was done using the Microsoft Excel 2010 version and analysis using SPSS version 20. Data is presented as frequencies and proportions. The difference between proportions of categorical variables was tested using Chi-square test and a p-value of less than 0.05 was taken as statistically significant.

\section{RESULTS}

The study included 540 pregnant women screened during the study period of one year among whom the incidence of oligohydramnios was $17.04 \% \quad(n=92)$. The sociodemographic and clinical variables of the participants are depicted in Table 1.

Table 1: Socio-demographic and clinical variables of the participants $(n=540)$.

\begin{tabular}{|c|c|c|}
\hline & Oligohydramnios ( $\mathrm{n=92}$ ) & Normal AFI $(\mathrm{n}=448)$ \\
\hline Mean age $( \pm S D)$ in years & $22.6 \pm 3.4$ & $25.8 \pm 2.9$ \\
\hline Mean gestational age in months & $38.3 \pm 7.2$ & $37.5 \pm 8.6$ \\
\hline \multicolumn{3}{|l|}{ Religion } \\
\hline Hindu & $44(48.1)$ & $236(52.7)$ \\
\hline Muslim & $28(30.6)$ & $117(26.1)$ \\
\hline Christian & $20(21.3)$ & $95(21.2)$ \\
\hline \multicolumn{3}{|l|}{ Monthly income } \\
\hline$<5000$ & $56(60.9)$ & $190(42.4)$ \\
\hline $5000-10000$ & $22(23.9)$ & $147(32.8)$ \\
\hline$>10000$ & $14(15.2)$ & $111(24.8)$ \\
\hline Gravida status & $12(8)$ & $14(9.3)$ \\
\hline Primigravida & $57(62)$ & $346(77.2)$ \\
\hline Multigravida & $35(38)$ & $102(22.8)$ \\
\hline
\end{tabular}

Figures in ( ) indicate column percentages. 
Table 2: Maternal outcomes of pregnancy $(n=540)$.

\begin{tabular}{|llll|}
\hline Mode of delivery & Oligohydramnios $(\mathbf{n = 9 2})$ & Normal AFI $(\mathbf{n = 4 4 8})$ & p-value* \\
\hline Vaginal & $40(43.5)$ & $258(57.6)$ & 0.01 \\
\hline Caesarean & $52(56.5)$ & $190(42.4)$ & \\
\hline Indications for caesarean & & & 0.004 \\
\hline Fetal distress & $23(44.2)$ & $126(66.4)$ & 0.016 \\
\hline Intra-uterine growth retardation & $18(34.6)$ & $36(18.9)$ & 0.27 \\
\hline Failed induction & $8(15.4)$ & $19(10)$ & 0.76 \\
\hline Mal-presentation (breech) & $3(5.8)$ & $9(4.7)$ & 0.59 \\
\hline Complications & & $154(34.4)$ & 0.019 \\
\hline Meconium stained liquor & $29(31.5)$ & $79(17.6)$ & 0.24 \\
\hline Post term pregnancy(>42 wks) & $26(28.3)$ & $70(15.6)$ & 0.01 \\
\hline Prolonged pregnancy $(>40-42$ wks) & $19(20.7)$ & $19(4.2)$ & 0.014 \\
\hline Pregnancy induced hypertension & $10(10.9)$ & $14(13.1)$ & \\
\hline Gestational diabetes & $8(8.7)$ & & \\
\hline
\end{tabular}

*chi-square test: $\mathrm{p}$-value $<0.05$ is significant.

Table 3: Perinatal outcomes of pregnancy $(n=540)$.

\begin{tabular}{|llll|}
\hline & Oligohydramnios $(\mathbf{n = 9 2})$ & Normal AFI $(\mathbf{n}=\mathbf{4 4 8})$ & p-value* \\
\hline Birth weight $<2.5 \mathrm{~kg}$ & $25(27.2)$ & $93(20.8)$ & 0.18 \\
\hline 1minute APGAR $<7$ & $14(15.2)$ & $54(12.1)$ & 0.4 \\
\hline 5 minute APGAR $<7$ & $11(12)$ & $24(5.4)$ & 0.02 \\
\hline Resuscitation required & $21(22.8)$ & $102(22.8)$ & 0.99 \\
\hline Admission in NICU & $30(32.6)$ & $35(7.8)$ & $<0.001$ \\
\hline Congenital anomalies & $3(3.3)$ & $1(0.2)$ & 0.001 \\
\hline Fetal death & $5(5.4)$ & $2(0.4)$ & 0.001 \\
\hline
\end{tabular}

Majority of the women with oligohydramnios (56.5\%) delivered by caesarean section compared to those with normal AFI (42.4\%) and this difference was statistically significant to establish the higher caesarean rates among those with oligohydramnios. IUGR was more associated indication among oligohydramnios pregnancies $(\mathrm{p}=0.001)$. The pregnancy complications like post term, pregnancy induced hypertension and gestational diabetes were more associated with oligohydramnios than normal pregnancies.

The incidence of low birth weight was higher $(27.2 \%)$ among those with oligohydramnios compared to normal AFI pregnancies but the difference was not statistically significant. The incidence of NICU admissions, congenital anomalies and fetal demise was statistically higher among the oligohydramnios compared to the normal AFI pregnancies.

\section{DISCUSSION}

Researchers worldwide have made many acclamations as how oligohydramnios is directly associated with maternal and fetal morbidities. This further emphasizes the need for a compulsory amniotic fluid level estimation as a part of ante-natal foetal surveillance. ${ }^{5}$ In the present research we compared the differences in maternal and fetal outcomes by following mothers with oligohydramnios and normal AFI at term.

The mean age of the study participants was 25.8 \pm 2.9 years whereas those with oligohydramnios were much younger (22.6 \pm 3.4 years). In the study done by Kaur $\mathrm{T}$ et al, the mothers with oligohydramnios were 25.8 years which was higher. ${ }^{6}$ The same study reported an incidence of oligohydramnios as $60 \%$ in primigravida. Another similar study by Sreelakshmi et al, found that the incidence of oligohydramnios was $73 \%$ in primigravida which is comparable to the present study which reported it as $62 \% .^{7}$

The caesarean section rate among oligohydramnios pregnancies reported in the present study was $56.6 \%$. This was similar to the study by Biradar et al, which documented $62 \%$ and Patel PK et al, where $81.25 \%$ underwent caesarean section and $16.67 \%$ induced labour. ${ }^{1,8}$ Bangal VB et al, contrastingly reported a normal spontaneous vaginal delivery rate of $56 \%$ and caesarean delivery rate as $44 \%$ among oligohydramnios pregnancies. ${ }^{9}$ Fetal distress $(44.2 \%)$ and IUGR (34.6\%) were the most common indications for caesarean sections in the present research. In the previous study also fetal distress $(42 \%)$ followed by intra uterine growth retardation $(18 \%)$ and failed induction $(13.4 \%)$ were the 
common indications. ${ }^{1}$ Another study by Sowmya K et al, showed that $50 \%$ of patients with oligohydramnios underwent caesarean section for fetal distress, $26.47 \%$ for intrauterine growth restriction (IUGR), $14.7 \%$ for failed induction and $8.82 \%$ for cephalo-pelvic disproportion which was similar to our study results. ${ }^{10}$

In the present study, the incidence of low birth weight among oligohydramnios was $27.2 \%$ which was not significantly higher than the normal AFI pregnancies. This rate was lower compared to the previous studies by Sowmya $\mathrm{K}$ et al, which reported a low birth weight rate of $48 \%$ and Biradar et al, showing $38.6 \% .^{1,10}$ The deliveries with a 5 minutes APGAR score $<7$ was significantly higher among the oligohydramnios complicated pregnancies $(12 \%)$ in the present study. This proportion was similar in another study by Sriya $\mathrm{R}$ et al, who documented $9.72 \%$ and higher $(17.5 \%)$ in another study by Bansal et al. ${ }^{10,11}$

The incidence of congenital anomalies like CTEV and renal agenesis was $3.3 \%$ among those with oligohydramnios. The incidence was much higher in previous studies like ranging from $5.8 \%$ in a study done by Shetty et al, an incidence of $11 \%$ by Golan et al, and an incidence of $8.5 \%$ in a study by Guin et al. ${ }^{12-14}$

\section{CONCLUSION}

The study clearly documented that when the amniotic fluid index of less than 5 at term was associated with adverse maternal pregnancy outcomes like increased caesarean section rates, post-dated deliveries, pregnancy induced hypertension, gestational diabetes and adverse perinatal outcomes like IUGR, low birth weight, congenital anomalies and foetal deaths. The study recommends that AFI surveillance needs to be an integral part of any antenatal foetal surveillance and decision making process while planning appropriate obstetric management.

Funding: No funding sources

Conflict of interest: None declared

Ethical approval: Not required

\section{REFERENCES}

1. Biradar KD, Shamanewadi AN. Maternal and perinatal outcome in oligohydramnios: study from a tertiary care hospital, Bangalore, Karnataka, India.
Int J Reprod Contracept Obstet Gynecol. 2016;5:2291-4.

2. Dutta DC. Textbook of Obstetrics, $8^{\text {th }}$ Ed. 2015:4344:250-251.

3. Moore TR. Clinical assessment of amniotic fluid. Clin Obstet Gynaecol. 1997;40(2):303-13.

4. Chate P, Khatri M, Hariharan C. Pregnancy outcome after diagnosis of oligohydramnios at term. Int $\mathbf{J}$ Reprod Contracept Obstet Gynaecol. 2013;2(1):23-6.

5. Ott WJ. Current perspective in antenatally surveillance ultrasound. Rev Obst Gynaecol. 2003;3:1-180.

6. Tajinder K, Ruchika S. Feto-maternal outcome in pregnancies with abnormal AFI. IOSR-JDMS. 2016;15(4):71-5.

7. Sreelakshmi U, Bindu T, Subhashini T. Impact of oligohydramnios on maternal and perinatal outcome: a comparative study. Int J Reprod Contracept Obstet Gynecol. 2018;7:3205-10.

8. Patel PK, Pitre DS, Gupta H. Pregnancy outcome in isolated oligohydramnios at term. Ntl $\mathbf{J}$ of Community Med. 2015;6(2):84-8.

9. Bangal VB, Giri PA, Sali BM. Incidence of oligohydramnios during pregnancy and its effects on maternal and perinatal outcome. J Pharma Biomed Sci. 2011;12(05):1-4.

10. Sriya R, Singhai S. Perinatal outcome in patients with amniotic fluid index $<5 \mathrm{~cm}$. J Obstet Gynaecol India. 2001;51:98-100.

11. Bansal D, Deodhar P. A Clinical Study of Maternal and Perinatal Outcome in Oligohydramnios. J Res Med Den Sci 2015;3(4):312-6.

12. Shetty A, Shetty S, Rai SB. A study of congenital anomalies and perinatal outcome in oligohydramnios. Int $\mathbf{J}$ Med Sci Public Health. 2013;2(4):1081-3.

13. Golan A, Lin G, Evron S, Arieli S, Niv D, David MP. Oligohydramnios: maternal complications and fetal outcome in 145 cases. Gynecol Obstet Invest. 1994;37(2):91-5.

14. Gita G, Punekar S, Lele A, Khare S. A Prospective Clinical Study of Feto-Maternal Outcome in Pregnancies with Abnormal Liquor Volume. J Obstet Gynaecol India. 2011;61(6):652-5.

Cite this article as: Jeyamani B, Anurekha JP, Arun Daniel J. Maternal and Perinatal outcomes of oligohydramnios in a tertiary care hospital in Salem, Tamil Nadu, India. Int J Reprod Contracept Obstet Gynecol 2019;8:1939-42. 